Check for updates

Cite this: RSC Adv., 2018, 8, 640

Received 26th September 2017 Accepted 16th December 2017

DOI: $10.1039 / c 7 r a 10641 f$

rsc.li/rsc-advances

\section{Oxygen vacancy and doping atom effect on electronic structure and optical properties of $\mathrm{Cd}_{2} \mathrm{SnO}_{4}$}

\begin{abstract}
Mei Tang, (D) ab JiaXiang Shang ${ }^{\mathrm{a}}$ and Yue Zhang ${ }^{\star a}$
The electronic structure and optical properties of oxygen vacancy and La-doped $\mathrm{Cd}_{2} \mathrm{SnO}_{4}$ were calculated using the plane-wave-based pseudopotential method based on the density functional theory (DFT) within the generalized gradient approximation (GGA). The formation energy of different oxygen vacancies showed that the $\mathrm{V}_{\mathrm{O} 2}$ oxygen vacancy was easy to obtain in experiments. The Bader charge analysis is implemented to directly observe the electron transfer and distribution for each atom. The calculated band structures show that when the oxygen vacancy was introduced, the impurity energy level appeared in the band gap. The impurity levels induced by oxygen vacancies were mainly composed of $\mathrm{O} 2 \mathrm{p}$ orbits and a very small amount of $\mathrm{Cd} 4 \mathrm{~s}$ orbits. After La doping based on the $\mathrm{V}_{\mathrm{O}_{2}}$ oxygen vacancy of $\mathrm{Cd}_{2} \mathrm{SnO}_{4}$, the Fermi energy level entered the conduction band and overlapped with the conduction band which increased the conductivity, and the band gap value increased to above $3.0 \mathrm{eV}$. The optical calculation results showed that the transmittance of the $\mathrm{V}_{\mathrm{O} 2}$ oxygen vacancy of $\mathrm{Cd}_{2} \mathrm{SnO}_{4}$ increased in short wavelength $(<600 \mathrm{~nm})$, the reflectivity increased in the infrared region compared with $\mathrm{Cd}_{2} \mathrm{SnO}_{4}$, and the transmittance increased to $90 \%$ in visible light region after La doping.
\end{abstract}

\section{Introduction}

Cadmium stannate (CTO), first discovered in 1960 by Smith, is an important transparent conductive material with great potential to be applied in thin film solar cells and other devices that require low resistance transparent conductive films. ${ }^{1-3}$ After grinding cadmium carbonate and tin oxide powder, the powder was sintered at high temperature, and the obtained cadmium stannate powder was determined by X-ray diffraction measurement. The $\mathrm{Cd}_{2} \mathrm{SnO}_{4}$ was light yellow and had an orthorhombic crystal structure, and the crystal lattice constant was also listed by Smith. ${ }^{4}$ Since then, researchers in the $1960 \mathrm{~s}$ studied $\mathrm{Cd}_{2} \mathrm{SnO}_{4}$, and Smith's work was repeated. In 1972, a $\mathrm{Cd}_{2} \mathrm{SnO}_{4}$ film was prepared by radioactive magnetron sputtering of a cadmium stannate ceramic target for the first time by Nozik. ${ }^{5}$ The sputtering atmosphere was mixed with argon and argon-oxygen atmosphere, and the film was annealed at low temperature for a long time. The optical bandgap and mobility of the film were measured to obtain a conductivity of $1.33 \times$ $10^{3} \Omega^{-1} \mathrm{~cm}^{-1}$. In 2000, after the use of CTO films for CdTe solar cells, $\mathrm{Cd}_{2} \mathrm{SnO}_{4}$ was gaining wide attention. ${ }^{6}$ In 2001 , Wu used CTO thin film as the transparent electrode of CdTe solar cells, and obtained $16.5 \%$ solar cell photoelectric conversion efficiency, the world's highest from CdTe. ${ }^{7}$

${ }^{a}$ School of Materials Science and Engineering, Beihang University, Beijing 100191, China. E-mail: zhangy@buaa.edu.cn

${ }^{b} J o u r n a l$ Publishing Center of Tsinghua University Press, Beijing 100084, China
A variety of methods for preparing the $\mathrm{Cd}_{2} \mathrm{SnO}_{4}$ film were then attempted, including chemical vapor deposition (CVD) method, ${ }^{8}$ pulsed laser deposition (PLD) method, ${ }^{9}$ spray pyrolysis method, ${ }^{\mathbf{1 0}}$ sol-gel method, ${ }^{\mathbf{1 1}, 12}$ electron beam evaporation method,,$^{13}$ DC sputtering ${ }^{14-17}$ and RF sputtering. ${ }^{18-21}$ In many of the preparation methods, the CTO films prepared by magnetron sputtering had the lowest resistivity, and the resistivity of films prepared by various magnetron sputtering methods was much lower compared with other methods. In all experiments using magnetron sputtering to deposit CTO thin films, we found that most of the deposited films were heat treated, ${ }^{22-24}$ and when the deposition atmosphere contained oxygen, the CTO film can be a low resistance film after heat treatment. The resistivity of the film deposited in the oxygen-containing atmosphere was higher, and the resistivity of the film after annealing in rare gas and reducing hydrogen was lower, and the resistivity of the film was higher after annealing in an oxygen-containing atmosphere. The resistivity of the films deposited in the argon atmosphere was low, but the resistivity results of different films obtained by different researchers after annealing in different atmospheres were different.

However, there were only a few detailed studies of the conductive mechanism of oxygen vacancy of the CTO thin films in the literature. ${ }^{25}$ For example, Stapiński et al. ${ }^{\mathbf{2 6}}$ prepared $\mathrm{Cd}_{2} \mathrm{SnO}_{4}$ thin films by DC reactive sputtering, analyzed the types of carriers in the films, it is considered that the carriers in the $\mathrm{Cd}_{2} \mathrm{SnO}_{4}$ film was oxygen vacancy or cadmium gap atom. But, oxygen vacancies or cadmium gap atoms provided more 
carriers that had not been studied. It had been suggested that cadmium atoms were occupied by tin atoms, which were also sources of carriers. ${ }^{27}$ Ion doping is a method to improve the optical absorption characteristics of materials by introducing different impurity ions, controlling the micro crystal structure and changing the band structure. The rare earth elements possess many special photoelectric properties because of their incomplete occupied $4 \mathrm{f}$ electron orbits and empty $5 \mathrm{~d}$ electron orbits, with rich electronic energy levels and long-lived excited states. They have become one of the new hotspots in the study of wide band gap semiconductor doping systems. By far, there have been no reports on La-doped $\mathrm{Cd}_{2} \mathrm{SnO}_{4}$ in experiments, and no profound theoretical calculation has been performed on the electronic structure and optical properties of $\mathrm{Cd}_{2} \mathrm{SnO}_{4}$ in compliance with the density function theory (DFT). In this study, we mainly calculated the effect of oxygen vacancy and doping atoms on the electronic and optical properties of CTO, and the obtained results can provide guidance for preparing $\mathrm{Cd}_{2} \mathrm{SnO}_{4}$ with high transparent conductive performance.

\section{Calculation methods}

The formation energy, electronic structure characteristics and optical properties were calculated by using the pseudopotential plane wave based on the density functional theory (DFT) incorporated in the VASP. ${ }^{\mathbf{8}, 29}$ The exchange and correlation energy was approximated by generalized gradient approximation (GGA). ${ }^{30}$ The valence electrons that make up the atoms were processed by the projector augment wave (PAW) scheme. ${ }^{31}$ Using the special $k$ point generated by the Monk-horst Pack method, ${ }^{32}$ the integral of the reciprocal lattice space was calculated. In order to overcome the band gap underestimation drawback of density function theory calculation, the calculation adopted the first-principle calculation with GGA $+U$ method. ${ }^{33}$ Through a series of tests, an effective $U_{\text {eff }}$ of 10,9 and $8 \mathrm{eV}$ was applied for $\mathrm{Cd}, \mathrm{Sn}$ and $\mathrm{O}$, which were adjusted to reach an agreement with the experimental band gap data. ${ }^{34}$ The plane wave cutoff energy is $500 \mathrm{eV}$ and the Monkhorst-Pack $k$-point sampling is $10 \times 6 \times 3$ for conventional cell of the $\mathrm{Cd}_{2} \mathrm{SnO}_{4}$.

\section{Results and discussion}

\section{A. The formation energy}

$\mathrm{Cd}_{2} \mathrm{SnO}_{4}$ possesses a space group of Pbam (No. 55) and an orthorhombic structure. ${ }^{35}$ The experimental lattice parameters of $\mathrm{Cd}_{2} \mathrm{SnO}_{4}$ are as follows: $\alpha=\beta=\gamma=90^{\circ}, a=3.24937, b=$ $5.66477, c=10.12710$, and the relaxed lattice parameters of pure $\mathrm{Cd}_{2} \mathrm{SnO}_{4}$ are $a=3.24928, b=5.66404, c=10.12371$, which are close to the experimental values. There are two oxygen sites in single $\mathrm{Cd}_{2} \mathrm{SnO}_{4}$ unit cell labeled as $\mathrm{O} 1$ and $\mathrm{O} 2 . \mathrm{V}_{\mathrm{O} 1}$ and $\mathrm{V}_{\mathrm{O} 2}$ indicate the case where the different site oxygen atom is removed to form an oxygen vacancy. The $2 \times 2 \times 1$ supercell containing $\mathrm{V}_{\mathrm{O} 1}$ and $\mathrm{V}_{\mathrm{O} 2}$ oxygen vacancy of $\mathrm{Cd}_{2} \mathrm{SnO}_{4}$ are built, using the $5 \times 5 \times 5 k$-points optimized structure. The convergence standard is set as the force on all atoms being less than $0.01 \mathrm{eV}^{-1}$. The optimized structure is used for the subsequent electronic structure and optical properties calculations.
The formation energy of $\mathrm{V}_{\mathrm{O} 1}$ and $\mathrm{V}_{\mathrm{O} 2}$ models is calculated according to the formula:

$$
E_{\mathrm{f}}=E_{\text {defect }}-E_{\text {perfect }}+\mu_{\mathrm{O}}
$$

Here, $E_{\text {defect }}$ and $E_{\text {perfect }}$ are the total free energies of the $\mathrm{Cd}_{2} \mathrm{SnO}_{4}$ without and with $\mathrm{V}_{\mathrm{O}}$. For oxygen-rich environments, $\mu_{\mathrm{O}}$ is chemical potential of $\mathrm{O}$, which is determined by the energy of oxygen molecule, $\mu_{\mathrm{O}}=\mu\left(\mathrm{O}_{2}\right) / 2 .{ }^{36}$ For oxygen-poor conditions, the chemical potential of oxygen atom is determined by $3 \mu_{\mathrm{O}}+$ $2 \mu_{\mathrm{La}}=\mu\left(\mathrm{La}_{2} \mathrm{O}_{3}\right)$. The formation energy values of $\mathrm{V}_{\mathrm{O} 1}$ and $\mathrm{V}_{\mathrm{O} 2}$ oxygen vacancy both in oxygen-rich and oxygen-poor conditions were $3.386,3.024 \mathrm{eV}$ and $-1.20,-1.56 \mathrm{eV}$. The $\mathrm{V}_{\mathrm{O} 2}$ model formation energy was lower than that of $\mathrm{V}_{\mathrm{O} 1}$ model, indicating that the $\mathrm{V}_{\mathrm{O} 2}$ oxygen vacancy has more stable energetic configuration with local lattice relaxation, so we chose $\mathrm{V}_{\mathrm{O} 2}$ oxygen vacancy in the next calculation. For $\mathrm{V}_{\mathrm{O} 2}$ oxygen vacancy of $\mathrm{Cd}_{2} \mathrm{SnO}_{4}$ supercell, the structure of La-doped $\mathrm{Cd}_{2} \mathrm{SnO}_{4}$ was modeled by replacing one $\mathrm{Cd}$ atom with one La atom, and the supercell models were in Fig. 1.

The La doping in $\mathrm{Cd}_{2} \mathrm{SnO}_{4}$ has been considered in different cases, including Cd-substituted $\left(\mathrm{La}_{\mathrm{Cd}}\right)$ and charge-compensated complex $4 \mathrm{La}_{\mathrm{Cd}} 3 \mathrm{~V}_{\mathrm{Sn}}$ (where $\mathrm{V}$ is denoted as vacancy). The calculated formation energies are 8.39, 1.58 and $-3.97 \mathrm{eV}$ for $\mathrm{La}_{\mathrm{Cd}}$ in charge states $+1,+2,+3$, respectively. The formation energy decreases as the entity charge state increases. The negative value means that $\mathrm{La}_{\mathrm{Cd}}{ }^{3+}$ formation is more energetically favorable than the other native point defects formed in the host lattice. Clearly, the formation energy of $\mathrm{La}_{\mathrm{Cd}}{ }^{3+}$ is the lowest, indicating that the $\mathrm{La}_{\mathrm{Cd}}{ }^{3+}$ has more stable energetic configuration with local lattice relaxation. To compensate the +3 charge, a $(3 / 4) \mathrm{V}_{\mathrm{Sn}}{ }^{4-}$ with opposite charge should be formed in order to keep the local neutrality. In consequence, a chargecompensated complex $4 \mathrm{La}_{\mathrm{Cd}} 3 \mathrm{~V}_{\mathrm{Sn}}$ is possibly formed. The formation energy is $-9.56 \mathrm{eV}$ for $4 \mathrm{La}_{\mathrm{Cd}} 3 \mathrm{~V}_{\mathrm{Sn}}$.

Calculation results show that if only formation energy is considered, a charge-compensated complex $4 \mathrm{La}_{\mathrm{Cd}} 3 \mathrm{~V}_{\mathrm{Sn}}$ should be most stable species after $\mathrm{La}$ is doped into $\mathrm{Cd}_{2} \mathrm{SnO}_{4}$ since its energy is the lowest among all possible types of defects. Nevertheless, the rest of defects may also become stable as temperature or the dopant concentration increases, and oxygen vacancies are easily generated in the reducing atmosphere during the preparation of oxides at high temperature. Therefore, it is necessary to investigate the coexistence of La atom and oxygen vacancies in theoretical calculations, the related research on charge compensation in unequal doping has been reported in the literature, ${ }^{37}$ so in the next calculation, we only assume one particular type of defect compensation mechanism (i.e. localised electronic compensation).

\section{B. Bader analysis}

In order to directly observe the distribution and transfer of electrons in each atom, the Bader charge analysis on the atoms around oxygen vacancy and La doping were investigated. As seen in Fig. 1, the electrotransferred from $\mathrm{Cd}$ and $\mathrm{Sn}$ atoms to $\mathrm{O}$ atoms in $\mathrm{V}_{\mathrm{O} 2}$ and doped systems. Table 1 shows the total charge and charge transfer of the nearest atoms of oxygen vacancy. For 


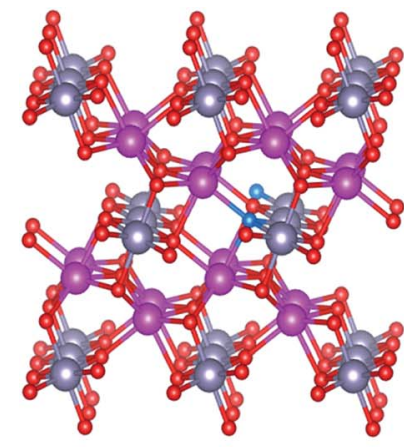

(a)

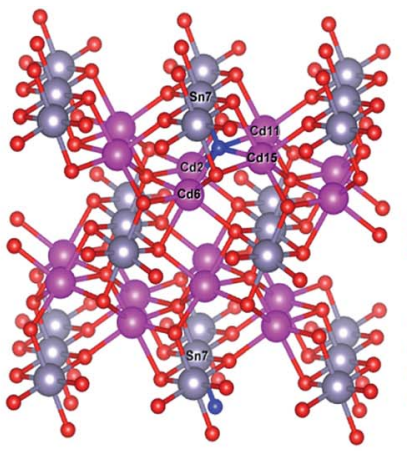

(b)

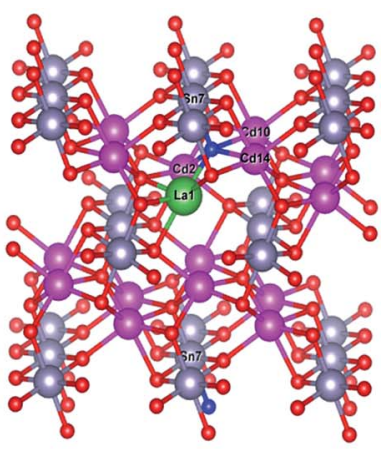

(c)

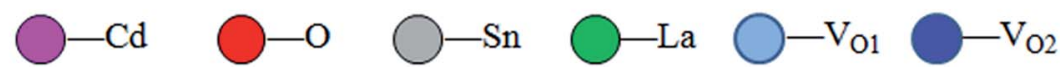

Fig. 1 The supercell models. (a) $\mathrm{V}_{\mathrm{O} 1}$ oxygen vacancy of $\mathrm{Cd}_{2} \mathrm{SnO}_{4}$ supercell; (b) $\mathrm{V}_{\mathrm{O} 2}$ oxygen vacancy of $\mathrm{Cd}_{2} \mathrm{SnO}_{4}$ supercell; (c) La-doped Cd $\mathrm{SnO}_{4}$ of $\mathrm{V}_{\mathrm{O} 2}$ oxygen vacancy supercell.

Table 1 The total charge and charge transfer of the nearest atoms of oxygen vacancy

\begin{tabular}{llll}
\hline Materials & Atoms & $\begin{array}{l}\text { Total Bader } \\
\text { charge }\end{array}$ & $\begin{array}{l}\text { Net charge } \\
\text { number }\end{array}$ \\
\hline CTO & O & 7.175 & -1.175 \\
& Cd & 10.776 & 1.224 \\
O-CTO & Sn & 11.683 & 2.317 \\
& O & 7.198 & -1.198 \\
& Cd2 & 10.952 & 1.048 \\
& Cd6 & 10.952 & 1.048 \\
& Cd11 & 11.026 & 0.974 \\
O-LaCTO & Cd15 & 11.000 & 1.000 \\
& Sn7 & 11.843 & 2.157 \\
& O & 7.210 & -1.210 \\
& Cd2 & 10.982 & 1.018 \\
& Cd10 & 10.916 & 1.084 \\
& Cd14 & 10.901 & 1.099 \\
& Sn7 & 12.430 & 1.570 \\
& La & 9.017 & 1.983
\end{tabular}

CTO system, $\mathrm{O}$ atoms are oxidized and the negative charges in $\mathrm{O}$ positions are -1.18 . The $\mathrm{Cd}$ atoms and $\mathrm{Sn}$ atoms are reduced, and the positive charge numbers are 1.22 and 2.32 respectively. Moreover, $\mathrm{Cd}$ and $\mathrm{Sn}$ atoms are hybridized with $\mathrm{O}$ atoms to a certain extent, which makes the outer electrons of $\mathrm{Cd}$ and $\mathrm{Sn}$ atoms transfer to the $\mathrm{O}$ atoms, resulting in $\mathrm{Cd}$ and $\mathrm{Sn}$ atoms losing electrons and behaving in their reduction state, while $\mathrm{O}$ atoms getting electrons with oxidation state.

For the $\mathrm{V}_{\mathrm{O} 2}$ oxygen vacancy of $\mathrm{Cd}_{2} \mathrm{SnO}_{4}$, the net charge value of the $\mathrm{O}$ atom varies little with an average of about -1.20 . The number of electrons lost by the $\mathrm{Cd}$ atoms is less than that without oxygen vacancies, the transfer electrons numbers approximately equal to $1.048,1.048,0.97,1.00$ and the number of electrons of $\mathrm{Sn}$ atom lost decreases to 2.16. For the La doped of $\mathrm{Cd}_{2} \mathrm{SnO}_{4}$, the net charge of $\mathrm{O}$ atoms is -1.21 , the number of electrons lost by the Cd atoms is 1.018, 1.084, 1.100, the number of electrons lost by $\mathrm{Sn}$ atom is 1.57 and the number of electrons lost by La atom is 1.98. After La doping, the $\mathrm{O} 2 \mathrm{p}$ orbital is hybridized with the La $5 \mathrm{~d}$ orbital, a large charge transfer of $1.98 e$ is found between $\mathrm{La}^{3+}$ and $\mathrm{O}^{2-}$ in the $\mathrm{La}-\mathrm{O}$ interaction. The net charge number of $\mathrm{Sn}$ atom is reduced, which indicates that there is a weaker interaction between $\mathrm{Sn}-\mathrm{O}$. In general, the charge analysis provides a picture of ionic interactions between the $\mathrm{Cd}$, Sn cations and $\mathrm{O}$ anions.

\section{Band structure and density of states}

Using the GGA $+U$ method, the calculated band gap value of $\mathrm{Cd}_{2} \mathrm{SnO}_{4}$ is $2.22 \mathrm{eV}$, which is in good accordance with the experimental band gap of the $\mathrm{Cd}_{2} \mathrm{SnO}_{4}\left(E_{\mathrm{g}}=2.3-2.5 \mathrm{eV}\right){ }^{38,39}$ Thus, the theoretical value agrees well with the experimental data and the selected $U$ values are reasonable. Fig. 2(a) shows the energy band dispersion curves along with six special $k$ points in the Brillouin zone of $\mathrm{Cd}_{2} \mathrm{SnO}_{4}$. The valence band maximum (VBM) and the conduction band minimum (CBM) are located at $\Gamma$ point of the Brillouin zone, which indicates that the $\mathrm{Cd}_{2} \mathrm{SnO}_{4}$ is a direct band-gap semiconductor. Fig. 2(b) and (c) show the band structure of the $\mathrm{V}_{\mathrm{O} 2}$ oxygen vacancy and $\mathrm{La}$ doped of $\mathrm{Cd}_{2} \mathrm{SnO}_{4}$. After the oxygen vacancy is introduced, the Fermi energy level is removed from the top of the valence band, and an impurity energy level caused by an oxygen vacancy in the forbidden zone is close to the Fermi energy level. After the introduction of La doping based on the $\mathrm{V}_{\mathrm{O} 2}$ oxygen vacancy of $\mathrm{Cd}_{2} \mathrm{SnO}_{4}$, the Fermi energy level enters the conduction band and overlaps with the conduction band which increases the conductivity and the band gap value increases to above $3.0 \mathrm{eV}$. The impurity energy level caused by oxygen vacancy in the forbidden zone is moved toward the valence band. The extreme values between local energy states above VBM and below CBM are placed in the different points, which means that the valence band and the local $\mathrm{O} 2 \mathrm{p}$ states of electronic transition can directly or indirectly move to the local Cd $4 \mathrm{~s}$, Sn $4 \mathrm{~d}$ and La $5 \mathrm{~d}$ or 


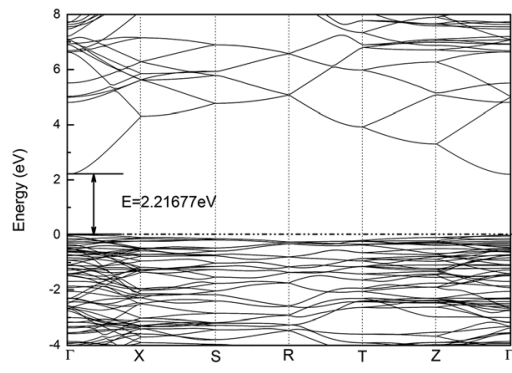

(a)

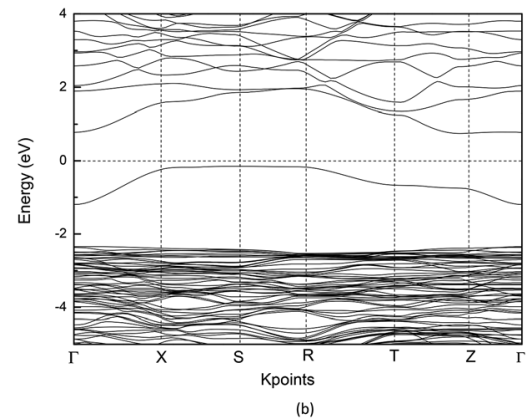

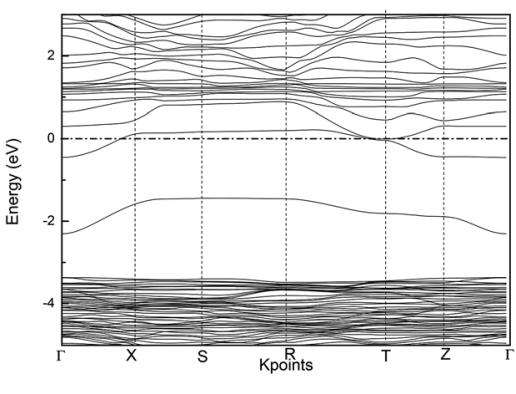

(c)

Fig. 2 (a) The band structure of the $\mathrm{Cd}_{2} \mathrm{SnO}_{4}$ using the GGA+U; (b) the band structure of the $\mathrm{V}_{\mathrm{O} 2}$ oxygen vacancy of $\mathrm{Cd}_{2} \mathrm{SnO}_{4}$; (c) the band structure of the $\mathrm{La}$ doped $\mathrm{Cd}_{2} \mathrm{SnO}_{4}$ based on the $\mathrm{V}_{\mathrm{O} 2}$ oxygen vacancy.

CBM, and these transitions lead to the change of the optical properties. ${ }^{40}$

The total and partial density of states (DOS) of the perfect $\mathrm{Cd}_{2} \mathrm{SnO}_{4}$ supercell crystal is presented in Fig. 3 . The conduction band is mainly composed of Cd $5 s$, Sn 5 s and Sn $5 p$ orbits, and the overlapping of $\mathrm{Cd} 4 \mathrm{~d}$ with $\mathrm{O} 2 \mathrm{p}$ makes up the valence band top. In contrast to $\mathrm{Cd}_{2} \mathrm{SnO}_{4}$, for $\mathrm{V}_{\mathrm{O} 2}$ oxygen vacancy and La doped of $\mathrm{Cd}_{2} \mathrm{SnO}_{4}$, some new local energy levels appear in the forbidden zone. The localized energy level of the under and near conduction band is mainly composed of Cd $4 \mathrm{~s}$, Sn $4 \mathrm{~d}$ and La $5 \mathrm{~d}$. The above and near valence bands are mainly composed of $\mathrm{O} 2 \mathrm{p}$ states. The local energy level caused by oxygen vacancy is mainly composed of $\mathrm{O} 2 \mathrm{p}$ orbital, with a very small amount of $\mathrm{Cd} 4 \mathrm{~s}$ states. The local energy levels caused by La doped oxygen vacancy of $\mathrm{Cd}_{2} \mathrm{SnO}_{4}$ are mainly composed of $\mathrm{O} 2 \mathrm{p}$ orbitals, with a very small amount of $\mathrm{Cd} 4 \mathrm{~s}$, Sn $4 \mathrm{~d}$ and La $5 \mathrm{~d}$ states. The local energy level above the valence band influences the conductivity. ${ }^{41,42}$

\section{Optical properties}

It is known that the optical properties are determined by the dielectric function $\varepsilon(\omega)=\varepsilon_{1}(\omega)+\mathrm{i} \varepsilon_{2}(\omega)$, which is mainly contributed from the electronic structures. ${ }^{43,44}$ The real part of

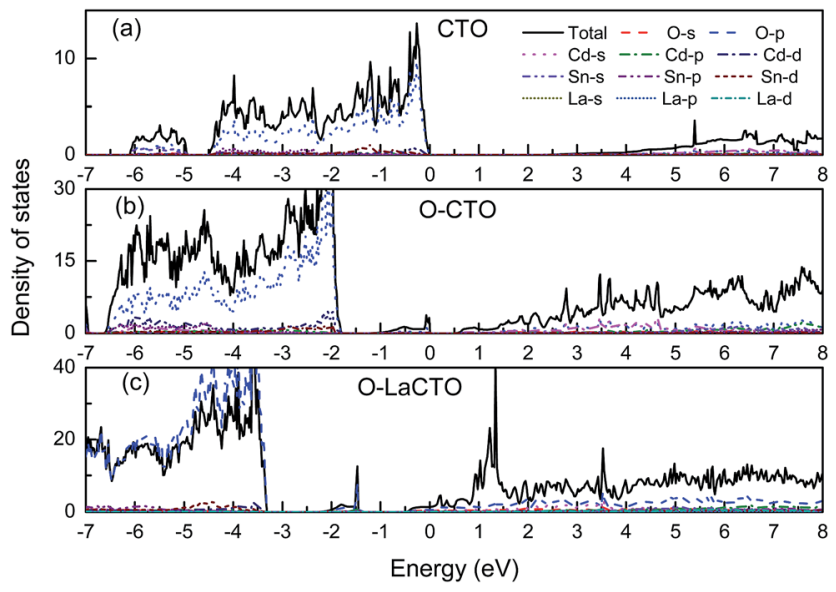

Fig. 3 Total and partial density of states of (a) perfect $\mathrm{Cd}_{2} \mathrm{SnO}_{4}$ and (b) the $\mathrm{V}_{\mathrm{O} 2}$ oxygen vacancy of $\mathrm{Cd}_{2} \mathrm{SnO}_{4}$ and (c) La-doped $\mathrm{Cd}_{2} \mathrm{SnO}_{4}$ based on the $\mathrm{V}_{\mathrm{O} 2}$ oxygen vacancy, respectively. this function, $\varepsilon_{1}(\omega)$ represents the dispersion of the incident photons by the materials, while the imaginary part $\varepsilon_{2}(\omega)$ results from the inter-band transition between the occupied state below Fermi level and the unoccupied state above top Fermi level due to the photon absorption. The real part of dielectric function $\varepsilon_{1}(\omega)$ can be evaluated from imaginary part $\varepsilon_{2}(\omega)$ through Kramer-Kronig relationship, where $\varepsilon_{2}(\omega)$ can be treated as detailing the real transitions between occupied and unoccupied electronic states for any materials..$^{4-48}$ All other optical constants, such as the absorption coefficient, refractive index and reflectivity can be derived from $\varepsilon_{1}(\omega)$ and $\varepsilon_{2}(\omega)$.

Therefore, the imaginary part of the dielectric function $\varepsilon_{2}(\omega)$ of perfect and $\mathrm{V}_{\mathrm{O} 2}$ oxygen vacancy and La doped of $\mathrm{Cd}_{2} \mathrm{SnO}_{4}$ is calculated, which is presented in Fig. 4. Considering the tensor nature of the dielectric function, the imaginary parts of the dielectric function are averaged over three polarization vectors $(x, y$, and $z)$ in our calculations. The peaks of the imaginary part of the dielectric function are related to the electron excitation. From Fig. 4, it can be seen that there are two major peaks located at 7.70 and $10.24 \mathrm{eV}$ for perfect $\mathrm{Cd}_{2} \mathrm{SnO}_{4}$. Combined with the density of states and electronic band structure analysis, the peaks in perfect $\mathrm{Cd}_{2} \mathrm{SnO}_{4}$ are mainly owing to the contribution of the direct electron transitions between the $\mathrm{O} 2 \mathrm{p}$ states in the upper valence band and $\mathrm{Cd} 4 \mathrm{~d}$, Sn $4 \mathrm{~s}$ states in the conduction band. As for $\mathrm{V}_{\mathrm{O} 2}$ oxygen vacancy and La doped of $\mathrm{Cd}_{2} \mathrm{SnO}_{4}$, the trend is similar with perfect $\mathrm{Cd}_{2} \mathrm{SnO}_{4}$, the main peaks of the $\mathrm{V}_{\mathrm{O} 2}$ oxygen vacancy of $\mathrm{Cd}_{2} \mathrm{SnO}_{4}$ locate at $1.80,2.30$, 10.10 and $15.76 \mathrm{eV}$. In the visible part there are two new peak positions of 1.8 and $2.3 \mathrm{eV}$, respectively. The first peak mainly comes from within the $\mathrm{O} 2 \mathrm{p}$ local energy states in forbidden band transition to the conduction band; and the second peak is caused by the valence band $\mathrm{O} 2 \mathrm{p}$ state transition to the conduction band. After the doped La atom, the main peaks are located at 2.00, 9.31 and $14.28 \mathrm{eV}$. The new peak in the visible part of the spectrum is at $2.0 \mathrm{eV}$, and the peak value is smaller compared with the $\mathrm{V}_{\mathrm{O} 2}$ oxygen vacancy of $\mathrm{Cd}_{2} \mathrm{SnO}_{4}$. A new peak is also found in the low energy around $0.40 \mathrm{eV}$ for the La-doped is originated by the excitation of $\mathrm{O} 2 \mathrm{p}$ electron from the top of valence band to the impurity energy level which is located at the bottom of the conduction band. Because of the introduction of local energy level, the electron transition between the deep valence band and the conduction band decreases, while the 

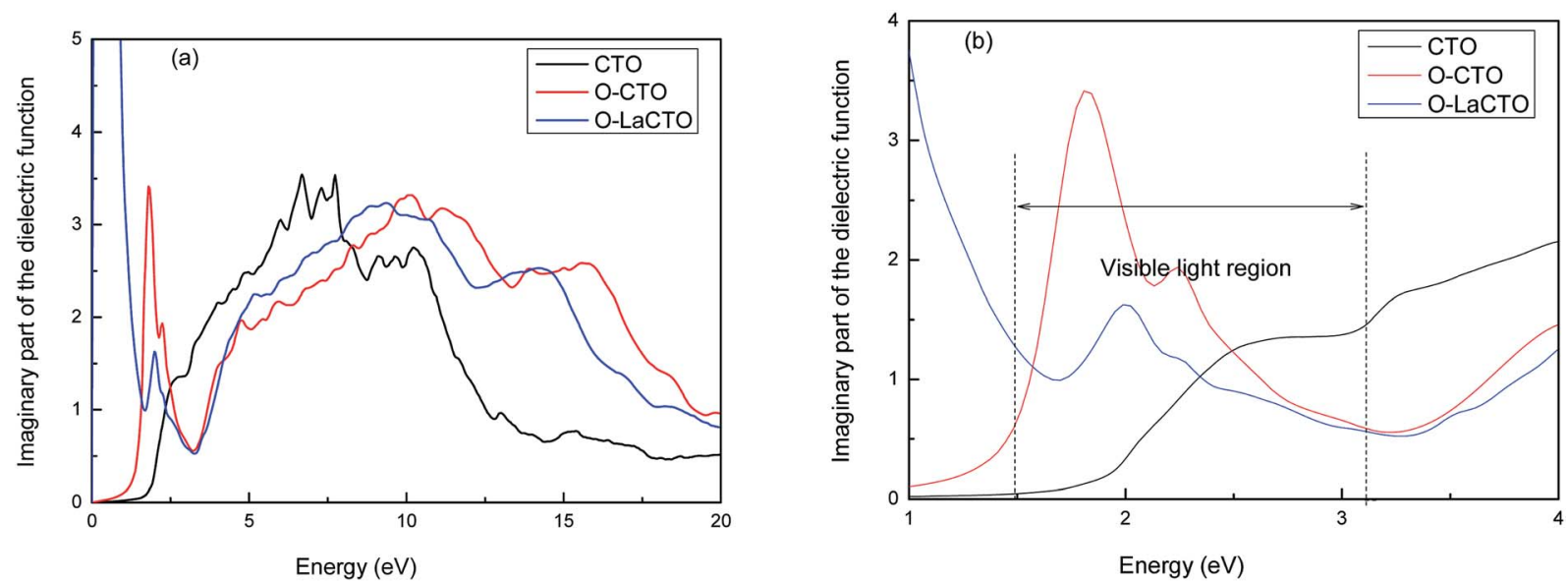

Fig. 4 The imaginary part of the dielectric function of perfect and $\mathrm{V}_{\mathrm{O}_{2}}$ oxygen vacancy and La doped of $\mathrm{Cd}_{2} \mathrm{SnO}_{4}(\mathrm{a})$; the visible light region part (b).

electron transition between the local energy level and the conduction band increases.

Transparent conducting materials require low absorption and reflectivity coefficient but high transmittance in the visible light region, so we calculated the absorption, reflectivity, refractive and transmittance. As is shown in Fig. 5(a), the absorption edge of perfect $\mathrm{Cd}_{2} \mathrm{SnO}_{4}$ in the visible light region is about $500 \mathrm{~nm}$, which is in conformity with experimental studies, while the optical absorption edge is about $800 \mathrm{~nm}$ for $\mathrm{V}_{\mathrm{O} 2}$ oxygen vacancy of $\mathrm{Cd}_{2} \mathrm{SnO}_{4}$ which is red shifted compare with the perfect $\mathrm{Cd}_{2} \mathrm{SnO}_{4}$. Oxygen vacancy enables the conduction band to move towards the lower energy, so that the electron
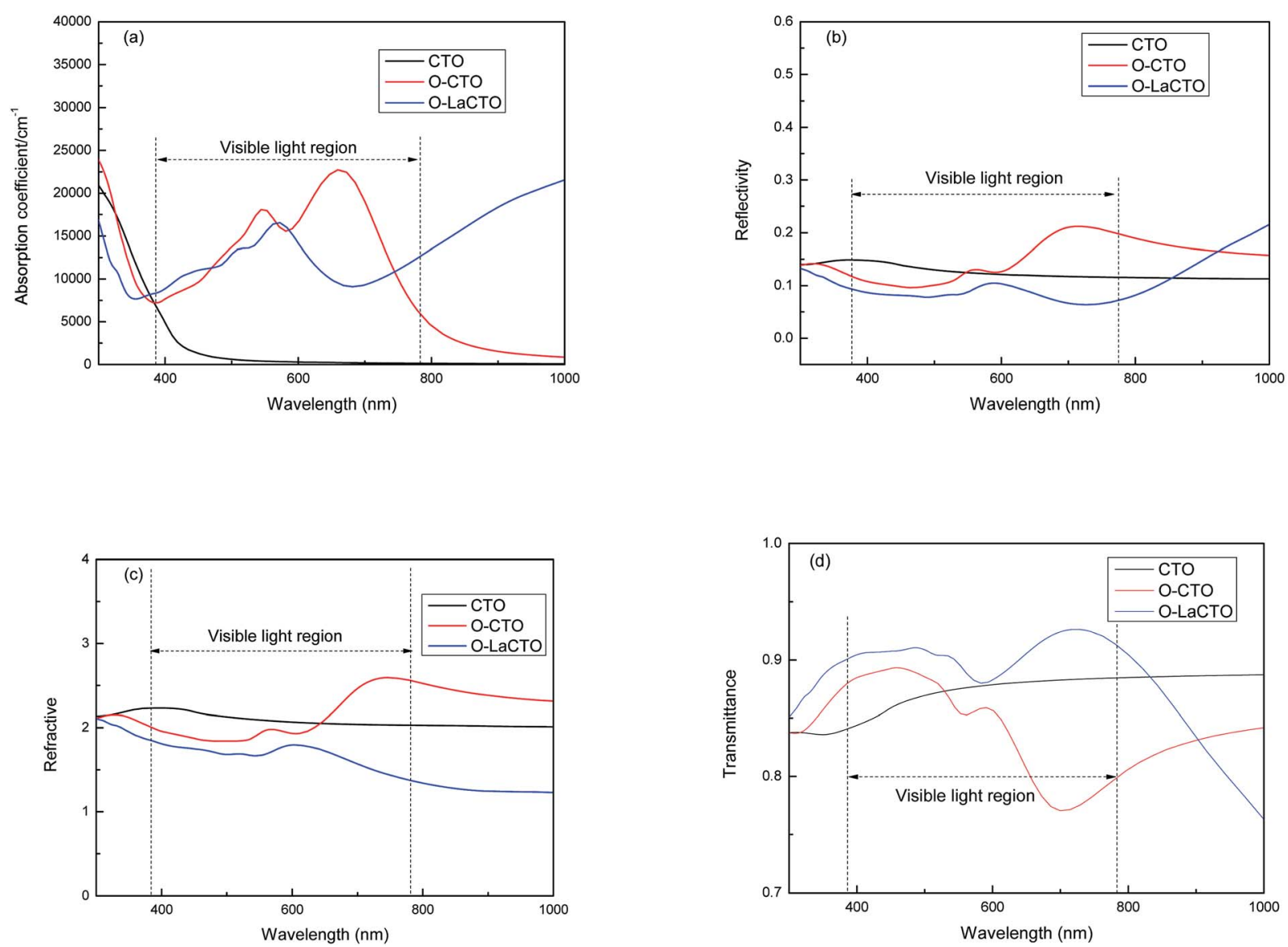

Fig. 5 The variation of the (a) absorption, (b) reflectivity, (c) refractive and (d) transmittance as a function of the wavelength of perfect and $\mathrm{V}_{\mathrm{O} 2}$ oxygen vacancy and La doped of $\mathrm{Cd}_{2} \mathrm{SnO}_{4}$. 
transition can be completed by absorbing only a smaller amount of energy, which eventually leads to the tendency of the absorption spectrum to move to the lower energy (red shift). After the doping of the La atom, the optical absorption coefficient decreases in the visible light region but increases in the infrared region compare with $\mathrm{V}_{\mathrm{O} 2}$ oxygen vacancy of $\mathrm{Cd}_{2} \mathrm{SnO}_{4}$. The reason why La doped $\mathrm{Cd}_{2} \mathrm{SnO}_{4}$ increases the absorption in infrared region is that the occupied states close to CBM are shallow donor states, and when the electrons in the local energy level transit to the bottom of the conduction band, these states induce a significant absorption in IR region.

In the visible light region of the spectrum as is shown in Fig. 5(b), it is clear that the perfect $\mathrm{Cd}_{2} \mathrm{SnO}_{4}$ has a low reflectivity (less than $15 \%$ ) in the visible and IR regions. However, this reflectivity is decreased in short wavelength $(<600 \mathrm{~nm})$ in visible light region and is significantly increased in long wavelength (>600 nm) up to infrared region for $\mathrm{V}_{\mathrm{O} 2}$ oxygen vacancy of $\mathrm{Cd}_{2} \mathrm{SnO}_{4}$. The reflectivity is the smallest (less than $10 \%$ ) after doping La atom. As for the refractive index, the trend is similar with reflectivity, as is shown in Fig. 5(c). The refractive index of CTO is about 2.1, and in the short wavelength $(<600 \mathrm{~nm})$ for $\mathrm{V}_{\mathrm{O} 2}$ oxygen vacancy of $\mathrm{Cd}_{2} \mathrm{SnO}_{4}$ the refractive index decreases. After La doping, the refractive index further decreases and the average value is 1.4 .

The average transmittance $(T)$ equals to $100 \%$ subtract the average reflectance $(R)$ and average absorption $(A)(T=100 \%-$ $R-A$ ). From Fig. 5(d) it can be concluded that the transmittance of CTO in the visible light region is about $85 \%$. The transmittance of the $\mathrm{V}_{\mathrm{O} 2}$ oxygen vacancy of $\mathrm{Cd}_{2} \mathrm{SnO}_{4}$ is increased in short wavelength $(<600 \mathrm{~nm})$ in visible light region but significantly decreased in long wavelength (>600 nm). After La doped, the transmittance increased to about $90 \%$ compared with $\mathrm{CTO}$ and $\mathrm{V}_{\mathrm{O} 2}$ oxygen vacancy of $\mathrm{Cd}_{2} \mathrm{SnO}_{4}$. It is indicated that the presence of oxygen vacancies is not conducive to the enhancement of the optical properties of transparent conducting materials. Therefore, it is necessary to control the occurrence of oxygen vacancies in the experiment and increase the transmittance by doping different atoms.

\section{Conclusions}

The electronic structure and optical properties of oxygen vacancy and La-doped $\mathrm{Cd}_{2} \mathrm{SnO}_{4}$ were calculated using the $\mathrm{GGA}+U$ method based on the first principles calculations. It was found that the impurity levels appeared in the forbidden band for $\mathrm{Cd}_{2} \mathrm{SnO}_{4}$ with oxygen vacancies, and the impurity levels caused by oxygen vacancy mainly were composed by $\mathrm{O} 2 \mathrm{p}$ orbital, mixed with a small amount of Cd 4 s orbital. After La doping, the Fermi level entered the conduction band, overlapping with the conduction band and the conductivity being improved. The results of Bader charge analysis showed that there was a slightly stronger interaction between $\mathrm{La}$ and $\mathrm{O}$ atoms but a weaker interaction between $\mathrm{Sn}$ and $\mathrm{O}$ atoms after $\mathrm{La}$ atom doping. The results of optical performance analysis showed that the transmittance caused by oxygen vacancy increased in short wavelength but decreased in long wavelength up to infrared region, and the transmittance of La atom doping increased in visible light region compared with $\mathrm{Cd}_{2} \mathrm{SnO}_{4}$. Therefore, it was necessary to increase the transmittance by doping different atoms in the experiment.

\section{Conflicts of interest}

There are no conflicts to declare.

\section{Acknowledgements}

This project was financially supported by the National Natural Science Foundation of China under Grants 51672014.

\section{References}

1 D. S. Ginley and C. Bright, MRS Bull., 2000, 25, 15-18.

2 T. Minami, MRS Bull., 2000, 25, 38-44.

3 T. J. Coutts, D. L. Young and X. N. Li, MRS Bull., 2000, 25, 5865.

4 A. J. Smith, Acta Crystallogr., 1960, 13, 749-752.

5 A. J. Nozik, Phys. Rev. B: Condens. Matter Mater. Phys., 1972, 6, 453-459.

6 X. Wu, R. Ribelin, R. G. Dhere, D. S. Albin, T. A. Gessert, S. Asher, D. H. Levi, A. Mason, H. R. Moutinho and P. Sheldon, Proceedings of the 28th IEEE Photovoltaic Specialists Conference, IEEE, 2000, pp. 470-474.

7 X. Z. Wu, Sol. Energy, 2004, 77, 803-814.

8 A. W. Metz, M. A. Lane, C. R. Kannewurt, K. R. Poeppelmeier and T. J. Marks, Chem. Vap. Deposition, 2004, 6, 297-300.

9 R. A. Ismail, S. A. Tawfiq, R. Hababa, R. S. Sabry and O. A. Abdulraza, e-J. Surf. Sci. Nanotechnol., 2007, 5, 152-154.

10 R. Kumaravel, V. Krishnakumar, V. Gokulakrishnan, K. Ramamurthi and K. Jeganathan, Thin Solid Films, 2010, 518, 2271-2274.

11 C. J. D. Godines, C. G. T. Castanedo, R. C. Pérez, G. T. Delgado and O. Z. Ángel, Sol. Energy Mater. Sol. Cells, 2014, 128, 150-155.

12 B. Schumm, P. Wollmann, J. Fritsch, J. Grothe and S. Kaskel, J. Mater. Chem., 2011, 21, 10697-10704.

13 H. M. Ali, H. A. Mohamed, M. M. Wakkad and M. F. Hasaneen, Jpn. J. Appl. Phys., 2009, 48, 041101.

14 N. Miyata, K. Miyake and S. Nao, Thin Solid Films, 1979, 58, 385-389.

15 N. Miyata, K. Miyake and Y. Yamaguchi, Appl. Phys. Lett., 1980, 37, 180-182.

16 A. M. Al-Baradi, M. M. El-Nahass, M. M. A. El-Raheem, A. A. Atta and A. M. Hassanien, Radiat. Phys. Chem., 2014, 103, 227-233.

17 M. M. El-Nahass, A. A. Atta, M. M. A. El-Raheem and A. M. Hassanien, J. Alloys Compd., 2014, 585, 1-6.

18 R. Mamazza Jr, D. L. Morel and C. S. Ferekides, Thin Solid Films, 2005, 484, 26-33.

19 K. Jeyadheepan, M. Thamilselvan, K. Kim, J. Yi and C. Sanjeeviraja, J. Alloys Compd., 2015, 620, 185-191.

20 S. M. Al-Sofiany and H. E. Hassan, J. Alloys Compd., 2015, 651, 149-156. 
21 S. H. Lee, E. W. Lee, S. Y. Park and C. W. Jeon, Mol. Cryst. Liq. Cryst., 2010, 532, 106-111.

22 D. L. Peng, S. R. Jiang and W. L. Wang, Chin. Phys. Lett., 1993, 10, 189-192.

23 W. L. Wang, K. J. Liao, C. Z. Cai, G. B. Liu and Y. Ma, Surf. Coat. Technol., 2003, 167, 284-287.

24 S. Y. Sun, J. L. Huang and D. F. Lii, J. Mater. Res., 2005, 20, 2030-2037.

25 T. J. Coutts, D. L. Young, X. Li and X. Wu, J. Vac. Sci. Technol., A, 2000, 18, 2646-2660.

26 T. Stapiński, E. Leja and T. Pisarkiewicz, J. Phys. D: Appl. Phys., 1984, 17, 407-413.

27 G. Haacke, W. E. Mealmaker and L. A. Siegel, Thin Solid Films, 1978, 55, 67-81.

28 G. Kresse and J. Furthmuller, Phys. Rev. B: Condens. Matter Mater. Phys., 1996, 54, 11169-11186.

29 G. Kresse and J. Furthmuller, Comput. Mater. Sci., 1996, 6, 15-50.

30 J. P. Perdew, K. Burke and M. Ernzerhof, Phys. Rev. Lett., 1996, 77, 3865-3868.

31 G. Kresse and D. Joubert, Phys. Rev. B: Condens. Matter Mater. Phys., 1999, 59, 1758-1775.

32 H. J. Monkhorst and J. D. Pack, Phys. Rev. B: Condens. Matter Mater. Phys., 1976, 13, 5188-5192.

33 X. G. Ma, Y. Wu, Y. H. Lv and Y. F. Zhu, J. Phys. Chem. C, 2013, 117, 26029-26039.

34 S. J. Wang, X. B. Shi and J. M. Li, RSC Adv., 2016, 6, 107865107870.
35 X. L. Huang, J. Lv, Z. S. Li and Z. G. Zhou, ChemInform, 2010, 41, 341-344.

36 C. G. Van de Walle and J. Neugebauer, J. Appl. Phys., 2004, 95, 3851-3879.

37 J. Han, L. J. Li, M. Y. Peng, B. L. Huang, F. J. Pan, F. W. Kang, L. Y. Li, J. Wang and B. F. Lei, Chem. Mater., 2017, 29, 84128424.

38 G. M. Zhang, Z. Y. Fu, Y. C. Wang, H. Wang and Z. Xie, RSC Adv., 2015, 5, 83922-83930.

39 S. Dinesh, M. Anandan, V. K. Premkumar, S. Barathan, G. Sivakumar and N. Anandhan, Mater. Sci. Eng., B, 2016, 214, 37-45.

40 D. Steiauf, J. L. Lyons, A. Janotti and C. G. Van de Walle, APL Mater., 2014, 2, 52.

41 A. Janotti and C. G. Van de Walle, Appl. Phys. Lett., 2005, 87, 122102.

42 M. Choi, A. Janotti and C. G. Van de Walle, J. Appl. Phys., 2013, 113, 044501.

43 A. Slassi, Optik, 2015, 126, 4751-4756.

44 J. F. Guo, W. Zhou, P. F. Xing, P. Q. Yu, Q. G. Song and P. Wu, Solid State Commun., 2012, 152, 924-928.

45 S. A. Kelkar, P. A. Shaikh, P. Pachfule and S. B. Ogale, Energy Environ. Sci., 2012, 5, 5681-5685.

46 A. Slassi, S. Naji, A. Benyoussef, M. Hamedoun and A. El Kenz, J. Alloys Compd., 2014, 605, 118-123.

47 R. S. Zhang, Y. Liu, Q. Gao, F. Teng, C. L. Song, W. Wang and G. R. Han, J. Alloys Compd., 2011, 509, 9178-9182.

48 H. Y. Yan, Y. R. Guo, Q. G. Song and Y. F. Chen, Phys. B, 2014, 434, 181-184. 